\title{
Peningkatan Pengetahuan Tentang Diet Gout Arthirits Melalui Pendidikan Kesehatan
}

\author{
${ }^{1}$ Syenshie Virgini Wetik, ${ }^{2}$ Cyntia Theresia Lumintang \\ ${ }^{1,2}$ Fakultas Keperawatan, Universitas Katolik De La Salle Manado, Kairagi I Kombos Manado, Kota \\ Manado, Sulawesi Utara 95000, Indonesia, sywetik@gmail.com; \\ Corresponding author: cyntiatheresialumintang@gmail.com
}

Received: 24 Oktober 2021; Revised: 29 Nopember 2021; Accepted: 1 Desember 2021

DOI: $10.52622 /$ jisk.v2i3.38

\begin{abstract}
The prevalence of gout arthritis is increasing due to the lack of information about the gout arthritis diet. This can be seen from the living habits of sufferers who do not understand the types of foods to avoid, consumption of foods with high purine levels, lack of exercise and rarely check their health conditions at health facilities. The purpose of this study was to increase the patient's knowledge about the gout arthritis diet by using health education methods in the form of lectures. This research was carried out with a quasi-experimental research design with a one group pretest - posttest approach on 30 gout arthritis patients in South Bongkudai Village, North Sulawesi. The sampling technique used was total sampling. The data collection instrument used a questionnaire related to age and gender as well as a questionnaire about dietary knowledge of gout arthritis. Data were analyzed through frequency distribution based on respondent characteristics and chi square test for bivariate analysis. The results showed that there was a significant increase in respondents' knowledge of $80 \%$ with the final result that there was an effect of providing health education on the level of patient knowledge about the gout arthritis diet with a $\mathrm{p}$ value of 0.0196 ( $\mathrm{p}$ value $<0.05$ ).
\end{abstract}

Keyword: gout arthritis diet, health education, level of knowledge

\begin{abstract}
Abstrak
Prevalensi gout arthritis semakin meningkat dipengaruhi oleh kurangnya informasi tentang diet gout arthritis. Hal ini dapat dilihat dari kebiasaan hidup penderita yang kurang memahami tentang jenis makanan yang harus dihindari, konsumsi jenis makanan dengan kadar purin tinggi, kurang berolahraga dan jarang memeriksakan kondisi kesehatan ke fasilitas kesehatan. Tujuan penelitian ini adalah untuk meningkatkan pengetahuan penderita tentang diet gout arthritis dengan metode penyuluhan kesehatan berupa ceramah. Penelitian ini telah dilaksanakan dengan desain penelitian quasi experiment dengan pendekatan one group pretest-postest pada 30 pasien gout arthritis di Desa Bongkudai Selatan, Sulawesi Utara. Teknik pengambilan sampling menggunakan total sampling. Intrumen pengumpulan data menggunakan kuesioner terkait usia dan jenis kelamin serta kuesioner tentang pengetahuan diet gout arthritis. Data dianalisis melalui distribusi frekuensi berdasarkan karakteristik responden dan uji chi square untuk analisis bivariat. Hasil penelitian menunjukkan bahwa terjadi peningkatan pengetahuan responden yang signifikan sebesar $80 \%$ dengan hasil akhir yaitu terdapat pengaruh pemberian pendidikan kesehatan terhadap tingkat pengetahuan pasien tentang diet gout arthritis dengan $\mathrm{p}$ value sebesar 0.0196 ( $\mathrm{p}$ value $<0.05$ ).
\end{abstract}


Kata kunci: diet gout arthritis, pendidikan kesehatan, tingkat pengetahuan

\section{PENDAHULUAN}

Peningkatan taraf hidup yang terjadi pada masyarakat Indonesia berdampak pula pada aspek kehidupan termasuk perubahan gaya hidup dan pola makan. Salah satu penyakit degeneratif yang termasuk akibat dari hal tersebut adalah gout arthritis. Gout arthritis adalah penyakit gangguan metabolik yang terjadi akibat dari penumpukan kristalisasi asam urat sehingga menyebabkan inflamasi pada sendi (12). Berdasarkan laporan Riskesdas tahun 2018, prrevalensi kasus gout di Indonesia berdasarkan hasil diagnosa dokter terbesar berada di Provinsi Aceh $(13,26 \%)$, Bengkulu $(12,11 \%)$, Bali $(10,46 \%)$ kasus terbesar pada kelompok usia > 65 tahun dan berjenis kelamin perempuan sebesar 8,46\% (Kementerian Kesehatan Republik Indonesia, 2018). Tahun 2013, World Health Organization (WHO) melaporkan bahwa dari total 95\% pasien gout di Indonesia hanya 24\% yang melakukan pemeriksaan medis dan $71 \%$ lainnya cenderung menggunakan obat bebas/ tradisional (8).

Gejala yang dirasakan berupa nyeri dan bengkak pada persendian akibat terjadinya perngkristalan pada cairan sendi (Naga, 2013). Penyebab terjadinya gout yaitu kebiasaan berlebih mengkonsumsi daging dan produk makanan laut, minuman beralkohol dan mengandung pemanis fruktosa, obesitas dan penggunaan obat jenis aspirin dan diuretika. Hal ini kemudian dapat berdampak terjadinya gagal ginjal (12). Untuk mencegah hal tersebut maka perlu dilakukan diet bagi klien dengan diagnose gout arthritis.

Perilaku diet bagi klien dengan gout dapat dilakukan dengan cara menghindari konsumsi jenis makanan dengan kandungan tinggi purin (jeroan, ampela dan hati hewani), konsumsi daging hewan berlebih (daging sapi, domba, babi), konsumsi makanan produk laut (lobster, udang, kepiting), konsumsi minuman dengan pemanis tinggi (jus buah, minuman jenis alcohol) dan mengontrol berat badan (18). Penyakit ini berdampak pada aktifitas harian penderita sehingga perlu dilakukan upaya untuk memotivasi pola hidup teratur dan sehat misalnya olahraga sepeda dan berenang, mengatur pola makan, menjaga berat badan, cek kesehatan secara rutin serta rajin kontrol kadar asam urat ke fasilitas pelayanan kesehatan terdekat misalnya dokter keluarga, petugas kesehatan dan kader kesehatan terlatih (14).

Berdasarkan laporan Dinas Kesehatan Provinsi Sulawesi Utara tahun 2018 tentang prevalensi gout arthirtis pada kategori lansia tercatat sebanyak 3.995 kasus. Sedangkan di Dinas Kesehatan Kota Manado tahun 2018 sebanyak 1.428 kasus (15). Hal ini menunjukkan bahwa tingkat kejadian gout arthritis di Sulawesi Utara berada pada level tinggi. Hasil survey yang dilakukan oleh Zhu, dkk (2011) di wilayah Sulawesi Utara mendapatkan hasil bahwa terdapat hubungan antara konsumsi alkohol dan kebiasaan makanan tinggi purin termasuk seafood dan terbukti meningkatkan resiko penyakit gout (7). Suku Minahasa termasuk dalam daftar suku dengan kecenderungan mengalami gout (10). Hal ini berkaitan dengan kegemaran dan budaya suku Minahasa yang gemar mengkonsumsi makanan laut sehingga menyebabkan prevalensi gout meningkat (19). Pada penelitian yang dilakukan di wilayah Puskesmas Kotabunan Bolaang Mongondow Timur didapatkan hasil bahwa kejadian gout arthritis berada pada kategori tinggi, pola makan penderita gout berada pada kategori kurang baik, sehingga terdapat hubungan antara pola makan dengan kejadian gout arthritis (5). Berdasarkan pemaparan data diatas maka perlu dilakukan upaya promotif dan preventif tentang pola diet bagi penderita gout arthritis melalui kegiatan pendidikan kesehatan. Tujuan dilakukan penelitian ini adalah mengetahui gambaran pengetahuan masyarakat tentang diet gout arthritis dan efektifitas pendidikan kesehatan terhadap peningkatan pengetahuan tentang diet pada penderita gout arthritis.

\section{METODE PENELITIAN}

Desain penelitian yang digunakan pada penelitian ini adalah pra-eksperimental dengan pendekatan one group pre-posttest design. Populasi pada penelitian ini terdiri dari 30 responden penderita gout arthritis dengan sampel menggunakan total sampling sehingga jumlah responden adalah 30 orang. Instrumen penelitian adalah kuesioner tentang pengetahuan penderita gout arthritis terhadap diet gout arthritis. 


\section{HASIL DAN PEMBAHASAN}

Berikut ini akan dipaparkan hasil penelitian yang diperoleh, antara lain:

Tabel 1. Karakteristik Responden $(\mathrm{n}=30)$

\begin{tabular}{|c|c|c|}
\hline Karakteristik & $\mathrm{f}$ & $\%$ \\
\hline \multicolumn{3}{|l|}{ Usia } \\
\hline $35-45$ tahun & 6 & 20 \\
\hline 46-55 tahun & 10 & 33,3 \\
\hline 56-65 tahun & 14 & 46,7 \\
\hline Total & 30 & 100 \\
\hline \multicolumn{3}{|l|}{ Jenis Kelamin } \\
\hline Laki-laki & 11 & 36,6 \\
\hline Perempuan & 19 & 63,4 \\
\hline Total & 30 & 100 \\
\hline
\end{tabular}

Berdasarkan tabel 1 diatas dapat dilihat bahwa karakteristik usia responden terbanyak adalah 56-65 tahun sebanyak 14 responden (46,7\%), 46-55 tahun sebanyak 10 responden (10\%), dan paling sedikit adalah usia 35-45 tahun dengan 6 responden (20\%). Sedangkan pada jenis kelamin responden paling banyak yaitu perempuan dengan 19 responden $(63,4 \%)$ dan laik-laki dengan jumlah 11 responden $(36,6 \%)$.

Dari hasil penelitian yang diperoleh maka sebagian besar responden dalam penelitian ini adalah berusia 56-65 tahun. Usia > 40 tahun rentan mengalami peningkatan asam urat. Hal ini terjadi karena perubahan metabolisme dalam tubuh termasuk perubahan fungsi ginjal dan memicu terjadinya gout arthritis (9). Kadar asam urat yang meningkat mengakibatkan penumpukan kristasl dalam pembuluh darah sehingga mempengaruhi fungsi sendi.

Jenis kelamin yang paling banyak adalah perempuan $(63,4 \%)$. Hal ini dipengaruhi karena adanya perubahan hormon estrogen yang signifikan terjadi pada wanita diatas usia 40 tahun dan berdampak pada kesehatan sendi. Hasil penelitian ini sejalan dengan hasil penelitian yang ditemukan bahwa 75,8\% responden wanita (Ayu, 2020). Hal yang sama ditemukan pada penelitian tentang gout arthritis yaitu sebagian besar responden $(96,9 \%)$ adalah wanita (6). Jenis kelamin perempuan dinyatakan lebih sensitif berespon terhadap nyeri. Peningkatan kadar asam urat erat kaitannya dengan kejadian setelah menaopause karena penurunan kadar hormon estrogen yang berdampak pada sekresi urin (4). Eksresi kadar asam urat pada wanita yang produksi hormon estrogennya berkurang (kondisi menopause) dapat menimbulkan peningkatan eskresi asam urat di ginjal sehingga menyebabkan terjadi hiperurusemia (16). Sehingga dapat disimpulkan bahwa kejadian gout arthritis erat kaitan jenis kelamin wanita terlebih khusus pada masa setelah menopause.

Tabel 2 Tingkat Pengetahuan Penderita Gout Arthritis Sebelum dan Sesudah Pemberian Pendidikan Kesehatan $(\mathrm{n}=30)$

\begin{tabular}{ccccc}
\hline Tingkat & \multicolumn{2}{c}{ Sebelum } & \multicolumn{2}{c}{ Setelah } \\
\cline { 2 - 5 } Pengetahuan & $\mathrm{f}$ & $\%$ & $\mathrm{f}$ & $\%$ \\
\hline Baik & 2 & 6,7 & 15 & 50 \\
\hline Sedang & 13 & 43,3 & 15 & 50 \\
\hline Kurang & 15 & 50 & 0 & 0 \\
\hline Total & 30 & 100 & 30 & 100 \\
\hline
\end{tabular}

Berdasarkan tabel 2 diatas, dapat dilihat bahwa tingkat pengetahuan responden tentang diet gout arthritis sebelum diberikan intervensi (pendidikan kesehatan) terbanyak berada pada kategori kurang dengan jumlah 15 responden (50\%), kategori sedang dengan jumlah 13 responden $(43,3 \%)$ dan kategori baik dengan jumlah 2 responden $(6,7 \%)$. Setelah diberikan intervensi maka terjadi perubahan pada tingkat pengetahuan responden yaitu kategori baik sebanyka 15 responden $(50 \%)$ dan kategori sedang sebanyak 15 responden (50\%). 
Tabel 3 Pengaruh Pendidikan Kesehatan terhadap Tingkat Pengetahuan Penderita Gout Arthritis $(\mathrm{n}=30)$

\begin{tabular}{|c|c|c|c|c|c|}
\hline \multirow{3}{*}{$\begin{array}{c}\text { Tingkat } \\
\text { Pengetahuan } \\
\text { Sebelum intervensi } \\
\text { (Pre-test) }\end{array}$} & \multicolumn{5}{|c|}{$\begin{array}{l}\text { Setelah intervensi } \\
\text { (post-test) }\end{array}$} \\
\hline & \multicolumn{2}{|c|}{ Baik } & \multicolumn{2}{|c|}{ Sedang + Kurang } & \multirow[t]{2}{*}{$\mathrm{p}$-value } \\
\hline & $\mathrm{f}$ & $\%$ & $f$ & $\%$ & \\
\hline Baik & 2 & 6,6 & 15 & 50 & \multirow{3}{*}{0,0196} \\
\hline Sedang + Kurang & 28 & 93,4 & 15 & 59 & \\
\hline Total & 30 & 100 & 30 & 100 & \\
\hline
\end{tabular}

Berdasarkan Tabel 3 diatas, dapat dilihat bahwa tingkat pengetahuan responden tentang diet gout arthritis sebelum diberikan intervensi mayoritas berada pada kategori sedang dan kurang, dan setelah diberikan intervensi mayoritas tingkat pengetahuan responden tentang diet gout arthritis berada pada kategori baik. Hasil analisis bivariat dengan uji chi square menunjukkan nilai $p=0.0196$ $(<0.05)$, sehingga dapat disimpulkan ada pengaruh pendidikan kesehatan terhadap tingkat pengetahuan penderita Gout Arthritis.

Pada penelitian ini didapatkan hasil terjadi peningkatan pengetahuan pada penderita gout arthritis setelah diberikan intervensi berupa pendidikan kesehatan dengan hasil kategori baik meningkat menjadi 50\% dan sedang $50 \%$. Hal ini sejalan dengan penelitian yang dilakukan di Karangmojo yang menunjukkan hasil sebanyak $84,4 \%$ meningkat pengetahuannya setelah diberikan edukasi (6). Menurut Notoadmojo, pengetahuan dapat didefinisikan sebagai hasil tahu pada suatu objek melalui penginderaan sehingga dengan meningkatkan pengetahuan maka memungkinkan seseorang untuk dapat menyelesaikan permasalahannya (2). Hal ini juga sejalan dengan penelitian Lumintang et al., pada tahun 2021 yang menunjukan pendidikan kesehatan tentang gout arthritis dapat memberikan pengetahuan pada penderita untuk menerapkan perilaku hidup sehat. Dengan adanya tingkat pemahaman yang baik tentang diet gout arthritis pada penderita gout dapat mempengaruhi perilaku penderita dalam memilih pola makan dan asupan nutrisi untuk mencegah kekambuhan gout arthritis.

Tujuan pemberian intervensi ini adalah agar dapat meningkatkan pengetahuan penderita gout tentang diet yang harus diterapkan dalam kehidupan sehari-hari. Jika tingkat pengetahuannya baik maka diharapkan dapat menghasilkan perilaku yang baik tentang diet gout arthritis misalnya rutin berolahraga, mampu memilih jenis asupan yang tinggi purin (jeroan, kacang, daging merah, dll) dan rutin memeriksakan kesehatan di fasyankes terdekat (1). Hal ini menjadi sangat penting dikarenakan tradisi dan budaya masyarakat di Sulawesi Utara yang gemar mengkonsumsi jenis makanan laut, daging-dagingan yang mengandung purin tinggi serta konsumsi alkohol. Hal ini yang memicu angka kejadian gout arthritis yang tinggi (9). Sehingga penting sekali untuk pemberian informasi tentang kebiasaan dan pola makan untuk menjaga kadar asam urat dalam batas normal melalui kegiatan pendidikan kesehatan tentang diet gout arthritis.

\section{KESIMPULAN}

Ada peningkatan pengetahuan penderita Gout Arthritis sebelum dan sesudah diberikan Pendidikan kesehatan. Hasil analisis bivariat menunjukan ada pengaruh pemberian Pendidikan kesehatan terhadap tingkat pengetahuan penderita Gout Arthritis dengan nilai $p=0.0196(<0.05$.

\section{DAFTAR PUSTAKA}

1. Aklima, N., Safrida, \& Husin, D. M. (2017). Pengetahuan dan Sikap Manula tentang Penyakit Rematik di Kemukiman Lamlhom Kecamatan Lhoknga Kabupaten Aceh Besar. Jurnal Ilmiah Mahasiswa Fakultas Keguruan dan Ilmu Pendidikan Unsyiah, 2(3), 20-25.

2. Almuhdar, A. S., Indria, D. M., \& Rusnianah, F. (2018). Efektifitas Pemberian e-Booklet Tentang Permasalahan Menyusui Terhadap Peningkatan Pengetahuan Dokter Umum di Puskesmas Kota Malang. Jurnal Kesehatan Islam: Islamic Health Journal, 7(01). https://doi.org/10.33474/jki.v7i01.973 
3. Ayu, S. M. T. (2020). Gambaran Pengetahuan Dan Perilaku Tentang Penatalaksanaan Rheumatoid Arthritis Oleh Penderita Di Desa Mancasan Wilayah Kerja Puskesmas Baki Sukoharjo. Universitas Muhammadiyah Surakarta, 20.

4. Cahyani, F. D., Surachmi, F., \& Setyowati, S. E. (2019). Effect on The Decrease Intensity Gymnastics Rheumatic Pain in Patients Gout Arthritis. JENDELA NURSING JOURNAL, 3(2), 89-97. https://doi.org/10.31983/jnj.v3i2.4657

5. Fauziah, N. R., Memah, H. P., \& Runtu, L. G. (2018). Pola Makan Mengandung Zat Purin Berlebihan Meningkatkan Prevalensi Gout Arthritis Pada Masyarakat Di Desa Kotabunan. Jurnal Ilmiah Perawat Manado, 6(2), 59-67.

6. Ferdiani, F. D. N., \& Yuliana, N. (2021). Pengaruh Penyuluhan Kesehatan Diet Gout Artritis terhadap Tingkat Pengetahuan Lansia di Desa Karangmojo. $2(1), 7$.

7. Fitriani, R., Mufti Azzahri, L., Nurman, M., \& Hamidi Syarif, N. M. (2021). Hubungan Pola Makan Dengan Kadar Asam Urat (Gout Artritis) Pada Usia Dewasa 35-49 Tahun. Jurnal Ners Universitas Pahlawan, 5(1). https://doi.org/10.31004/jn.v5i1.1674

8. Hardianti, I., \& Mayasari, D. (2020). Penatalaksanaan Gout Arthritis dan Hipertensi Grade I pada Wanita Lansia Obesitas melalui Pendekatan Dokter Keluarga. Medula, 10(1). http://repository.lppm.unila.ac.id/25836/1/Intan\%20Hardianti\%20Gout\%20April\%202020.p df

9. Imbar, H. S., Legi, N. N., \& Pinunsanda, J. D. (2018). Asupan Purin Terhadap Kadar Asam Urat Pada Penderita Gout Arthritis Di Wilayah Kerja Puskesmas Ranotana Weru. Jurnal GIZIDO, 10(2), 69-72. https://doi.org/10.47718/gizi.v10i2.739

10.Junaidi, I. (2013). Rematik dan Asam Urat (Revisi). Bhuana Ilmu Populer. http://library.poltekkesjambi.ac.id/opac/detail-opac?id=1705

11.Kementerian Kesehatan Republik Indonesia. (2018). Laporan Nasional Riskesdas 2018. Sekretariat Badan Litbang, Kemenkes RI. https://dinkes.kalbarprov.go.id/wpcontent/uploads/2019/03/Laporan-Riskesdas-2018-Nasional.pdf

12.Lemone, P., Burke, K. M., \& Bauldoff, G. (2016). Buku Ajar Keperawatan Medikal Bedah Gangguan Muskuloskeletal (5th ed., Vol. 3). Penerbit Buku Kedokteran EGC.

13.Lumintang, C., Suprapti, F., \& Tjitra, E. (2021). Efektivitas Intervensi Keperawatan 4Es terhadap Perubahan Kadar Asam Urat, Perilaku Hidup, dan Kualitas Hidup Penderita Gout Arthritis. Jurnal Keperawatan, 13(2), 393-402. https://doi.org/https://doi.org/10.32583/keperawatan.v13i2.1506

14.Madyaningrum, E., Kep, S., Kes, M., Kusumaningrum, F., Wardani, R. K., Gz, S., Susilaningrum, A. R., Kep, S., Ramadhani, A., \& Kep, S. (2020). Buku Saku Kader Pengontrolan Asam Urat Di Masyarakat. Fakultas Kedokteran, Kesehatan Masyarakat dan Keperawatan (FK-KMK) UGM, 1, 38 .

15.Manoppo, M. T. L., Ratag, B. T., \& Mantjoro, E. M. (2019). Hubungan Antara Konsumsi Purin Riwayat Keluarga Dan Jenis Kelamin Dengan Kejadian Hiperurisemia Pada Lansia Di Kelurahan Malalayang I Timur. 8(7), 6.

16. Moriwaki, Y. (2014). Effects on Uric Acid Metabolism of the Drugs except the Antihyperuricemics. Journal of Bioequivalence \& Bioavailability, 06(01). https://doi.org/10.4172/jbb.1000173

17.Naga, S. S. (2013). Ilmu Penyakit Dalam Buku Panduan Lengkap (Vol. 4). Yogyakarta Diva Press.

18.Perhimpunan Reumatologi Indonesia. (2018). Pedoman Diagnosis dan Pengelolaan Gout. Perhimpunan Reumatologi Indonesia. https://reumatologi.or.id/download/pedomandiagnosis-dan-pengelolaan-gout/

19.Wurangian, V. G., N., Kepel, B., \& Manampiring, A. E. (2013). Gambaran Asam Urat Pada Remaja Obes Di Kabupaten Minahasa. Fakultas Kedokteran Universitas Sam Ratulangi, Skripsi. Published. 